$16^{\circ}$ USIHC - Congresso Internacional de Ergonomia e Usabilidade de CINAHPA

\title{
APROPRIAÇÃO EM ESPAÇOS PÚBLICOS DE JUIZ DE FORA: UMA FERRAMENTA DE ANÁLISE
}

\section{APPROPRIATION OF PUBLIC SPACES OF JUIZ DE FORA: AN ANALYSIS TOOL}

\author{
Jéssica de Souza Christo ${ }^{1}$, graduanda \\ Laísy Damiani Pinheiro Rocha², graduanda \\ (1) Universidade Federal de Juiz de Fora (UFJF) \\ e-mail: jessica.christo@arquitetura.ufjf.br \\ (2) Universidade Federal de Juiz de Fora (UFJF) \\ e-mail: laisy.rocha@yahoo.com.br
}

Apropriação, identidade, espaços públicos urbanos

Este estudo busca, como objetivo geral, apresentar uma ferramenta desenvolvida par a análise da apropriação em espaços públicos. Para seu embasamento, foi adotada a técnica de documentação indireta. Já no tocante à estrutura do instrumento, foram empregadas as técnicas da observação participante e da entrevista semi-estruturada.

Appropriation, identity, public urbans spaces

This study aims, as a general objective, to present a tool developed by an analysis of the appropriation in public spaces. For its foundation, an indirect documentation technique was adopted. No longer concerning the structure of the instrument, they were used as techniques of participatory observation and semi-structured interview.

\section{Introdução}

A manutenção da identidade de uma cidade, passa pela existência de um enlace entre a sua população e seus espaços públicos. A identidade da cidade está intimamente ligada à apropriação desses locais, pois neles ocorrem diversas interações não somente entre os seus usuários mas destes com o meio. Sendo assim, é importante entender como a população se apropria desses espaços.
O objetivo geral deste trabalho é apresentar, em síntese, uma ferramenta de análise da apropriação, a ser aplicada em espaços públicos da cidade de Juiz de Fora, estado de Minas Gerais, Brasil. O estudo aqui apresentado compreende, além desta introdução, a sua fundamentação teórica, focalizada em conceitos relacionados à apropriação, a metodologia adotada, a apresentação do instrumento de análise, as 


\section{$16^{\circ}$ \\ ERGODESIGN USIHC CINAHPA}

considerações finais, a bibliografia utilizada e os agradecimentos.

\section{Fundamentação Teórica}

Neste ponto, são abordados alguns conceitos e temas que embasaram a elaboração da ferramenta, como espaços públicos; percepção ambiental; apropriação; identidade; topofilia; lugar; e acessibilidade.

Primeiramente, é preciso compreender o que são os espaços públicos. Segundo Leite [2004. P. 196],

[...] entende-se que uma noção de espaço público requer, para qualificar como públicos determinados espaços urbanos da vida contemporânea, uma inserção conceitual de mão dupla entre espaço e sociabilidade pública. Implica, portanto, relacionar dois processos interdependentes, que concorrem simultaneamente para uma única direção: a construção social do espaço, enquanto produto e produtor de práticas sociais; e a construção espacial da sociabilidade pública, enquanto produto e produtor das espacializações da vida social.

O processo perceptivo é estabelecido por Del Rio [1999, p. 3] "[...] como um processo mental de interação do indivíduo com o meio ambiente [...].

O processo de percepção permite $o$ estabelecimento de um vínculo entre o indivíduo e o meio, evidenciado por meio de seu comportamento e consequente apropriação do espaço. A apropriação, segundo Cavalcante e Elias [2011, p. 63], "[...] significa também exercer domínio sobre um espaço e objetos, embora não seja necessário ter sua posse legal".

O processo de apropriação pressupõe a existência da afetividade. A afetividade pode ser definida como "[...] um conjunto de sentimentos e emoções, acerca de alguém, algo ou algum lugar" [OLINTO, s/d, p.169].

A partir do afeto entre o indivíduo e o meio, há uma identidade comum entre ambos. Serpa [2004, p.25] afirma que "[...] identidades constroem-se $16^{\circ}$ Ergodesign - Congresso Internacional de Ergonomia e Usabilidade de Interfaces Humano Tecnológica: Produto, Informações Ambientes Construídos e Transporte

$16^{\circ}$ USIHC - Congresso Internacional de Ergonomia e Usabilidade de Interfaces Humano Computador

CINAHPA | 2017 - Congresso Internacional de Ambientes Hipermídia para Aprendizagem.

sempre a partir do reconhecimento de uma alteridade", o que só é possível "[...] onde há interação, transações, relações ou contatos entre grupos diferentes" [Barth, 1969, apud Uriarte, 2001]. Tuan [1980] denomina esse enlace como topofilia, que, por sua vez, engloba "todos os laços afetivos dos seres humanos com o meio ambiente material" [TUAN, 1980, p. 107].

Assim, uma vez que ao espaço é atribuído um significado, tem-se a caracterização do lugar [TUAN, 1983].

Augé [1994, p. 53] afirma que,

[...] o lugar é necessariamente histórico a partir do momento em que, conjugando identidade e relação, ele se define por uma identidade mínima. Por isso é que aqueles que nele vivem podem aí reconhecer marcos que não tem de ser objetos de conhecimento

Para que um espaço possa ser considerado por todos como um lugar, é necessário que exista uma aproximação entre os conceitos de apropriação e acessibilidade.

De acordo com a NBR 9050/15 da Associação Brasileira de Normas Técnicas - ABNT - principal norma brasileira sobre acessibilidade - a acessibilidade pode ser definida como a
possibilidade e condição de alcance, percepção e entendimento para utilização, com segurança e autonomia, de espaços, mobiliários, equipamentos urbanos, edificações, transportes, informação e comunicação, inclusive seus sistemas e tecnologias, bem como outros serviços e instalações abertos ao público, de uso público ou privado de uso coletivo, tanto na zona urbana como na rural, por pessoa com deficiência ou mobilidade reduzida. (ABNT, 2015, p. 2).

Assim, tem-se definidos alguns dos principais conceitos relacionados à apropriação.

O entendimento acerca de tais pontos, por sua vez, é essencial para o embasamento do instrumento e sua elaboração. 


\section{$16^{\circ}$ \\ ERGODESIGN USIHC CINAHPA}

\section{Metodologia}

Para este trabalho, foi adotada a técnica da documentação indireta. Esta, consiste, segundo Marconi e Lakatos [2003], na realização de um pesquisa bibliográfica sobre temas relacionados ao assunto abordado, sendo aqui empregada para a concretização da fundamentação teórica.

Já o trabalho, apresenta uma ferramenta composta por duas técnicas e desenvolvida para análise da apropriação: a observação participante e a entrevista semi-estruturada.

A observação participante consiste, de acordo com Marconi e Lakatos [2003, p. 194],

[...] na participação real do pesquisador com a comunidade ou grupo. Ele se incorpora ao grupo, confunde-se com ele. Fica tão próximo quanto um membro do grupo que está estudando e participa das atividades normais deste.

Cabe aqui mencionar que a observação participante deve ser acompanhada pelo levantamento fotográfico dos espaços estudados.

Quanto a entrevista semi-estruturada, é dito por Manzini [2004, s/p] que,

geralmente a entrevista é indicada para buscar informações sobre opinião, concepções, expectativas, percepções sobre objetos ou fatos ou ainda para complementar informações sobre fatos ocorridos que não puderam ser observados pelo pesquisador, [...].

Tem-se ainda, de acordo com Manzini [1990/1991, p. 154], que na entrevista semi-estruturada,

[...] a resposta não está condicionada a uma padronização de alternativas formuladas pelo pesquisador, como ocorre na entrevista com dinâmica rígida. Geralmente, a entrevista semi-estruturada está focalizada em um objetivo sobre o qual confeccionamos um roteiro com perguntas principais, completadas por outras questões inerentes às circunstâncias momentâneas à entrevista. $16^{\circ}$ Ergodesign - Congresso Internacional de Ergonomia e Usabilidade de Interfaces Humano Tecnológica: Produto, Informações Ambientes Construídos e Transporte

$16^{\circ}$ USIHC - Congresso Internacional de Ergonomia e Usabilidade de Interfaces Humano Computador

CINAHPA | 2017 - Congresso Internacional de Ambientes Hipermídia para Aprendizagem.

Com isso, sabe-se que a entrevista semiestruturada, baseia-se em um roteiro previamente estruturado, mas que possui o benefício da flexibilização.

\section{A Ferramenta}

Com base na fundamentação teórica e na metodologia adotada, foi elaborada uma ferramenta de análise da apropriação em espaços públicos urbanos.

O instrumento é composto por duas etapas:

- Observação participante;

- Entrevista semi-estruturada.

No que tange a escolha das técnicas utilizadas nas duas etapas, levou-se em consideração, além de ambas atenderem ao tema, a ocorrência de interação entre o pesquisador e o meio. Com isso, enquanto a observação participante tem como foco o comportamento, as entrevistas analisam a percepção.

Quanto a aplicação, esta deve ser realizada por áreas da cidade pré-estabelecidas, com dimensões próximas a um quarteirão e durar - já contemplando o tratamento dos dados - cerca de um mês.

A aproximação entre os conceitos de apropriação e acessibilidade, apontada na fundamentação teórica, pode ser verificada nas duas etapas que compõem a ferramenta (observação participante e entrevista semi-estruturada). Dessa maneira, poder-se-á verificar possíveis relações entre soluções e problemas em acessibilidade existentes nos espaços e o comportamento das pessoas.

Tal produto, por sua vez, irá contribuir para uma análise conjunta apropriação/acessibilidade, já prevista, com dados fornecidos por uma ferramenta de avaliação da acessibilidade desenvolvida paralelamente - a ser aplicada nos mesmos espaços públicos.

O instrumento deve ser aplicado em espaços
Realização:

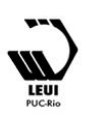




\section{$16^{\circ}$ \\ ERGODESIGN USIHC CINAHPA}

públicos existentes na cidade de Juiz de Fora.

Neste contexto, especialmente na área central, destacam-se, além das ruas, calçadões, galerias e praças. Em conjunto, esses espaços, geram uma alternativa ao fluxo contínuo de pedestres.

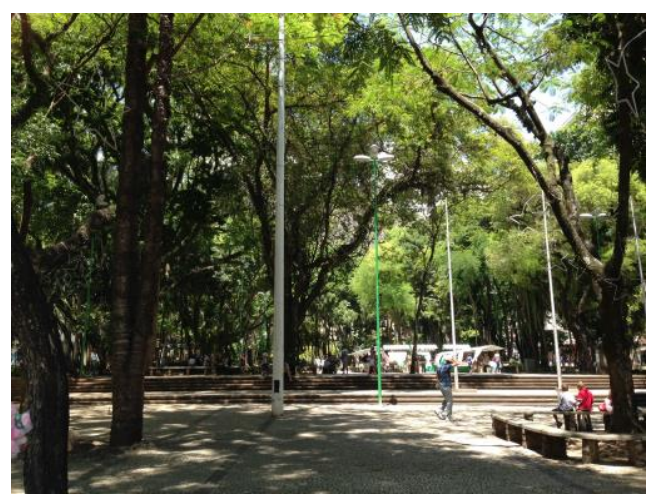

Figura 01 - Parque Halfeld, localizado no centro da cidade de Juiz de Fora. Fonte: arquivo próprio.

As praças, segundo Fonseca e Filho [2016, p. 166] presenciaram toda a evolução do centro de Juiz de Fora, sendo espaços para a permanência no dia a dia e a realização de atividades cívicas e festas. $\mathrm{O}$ mesmo pode ser afirmado com relação a ruas localizadas na área central da cidade, como a Rua Halfeld, a Avenida Getúlio Vargas, a Avenida Presidente Itamar Franco (antiga Avenida Independência) e a Avenida Barão do Rio Branco. No tocante às praças, são importantes exemplos o Parque Halfeld e a Praça Doutor João Penido, mais conhecida como Praça da Estação.

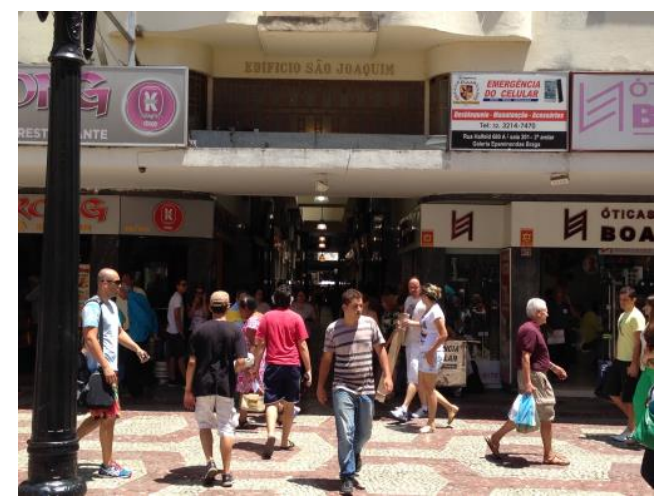

Figura 02 - Galeria Epaminondas Braga, localizado no centro da cidade de Juiz de Fora. Fonte: arquivo próprio. $16^{\circ}$ Ergodesign - Congresso Internacional de Ergonomia e Usabilidade de Interfaces Humano Tecnológica: Produto, Informações Ambientes Construídos e Transporte

$16^{\circ}$ USIHC - Congresso Internacional de Ergonomia e Usabilidade de Interfaces Humano Computador

CINAHPA | 2017 - Congresso Internacional de Ambientes Hipermídia para Aprendizagem.

As galerias, por sua vez, são exemplares arquitetônicos do século $\mathrm{XX}$, decorrentes de um período de mudanças no cenário econômico da cidade [FONSECA; FILHO, 2016]. A Galeria Pio $\mathrm{X}$, localizada no centro da cidade, foi a primeira a ser construída.

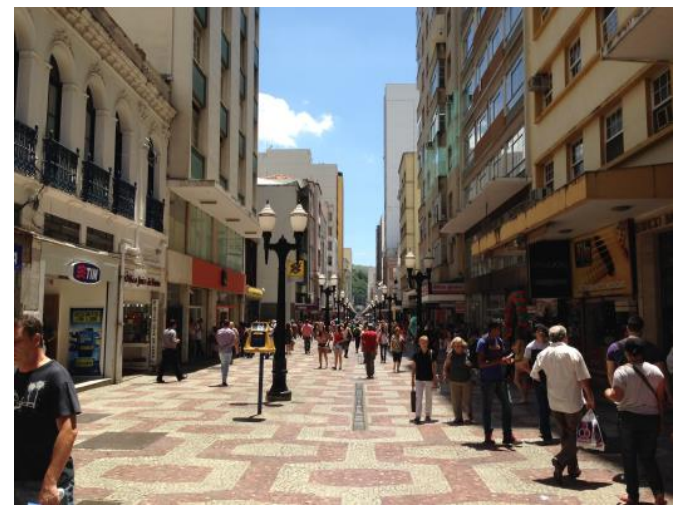

Figura 03 - Calçadão da Rua Halfeld, localizado no centro da cidade de Juiz de Fora. Fonte: arquivo próprio.

Já os calçadões, fazem parte de uma configuração mais recente.

Diferentemente da galeria, que é uma tipologia que se originou na Europa e passou a ser adotada aqui com alguma demora, o calçadão começou a ser implantado em Juiz de Fora juntamente com seu ápice observado em todo o mundo, durante a década de 1970.

[FONSECA; FILHO, 2016, p. 166].

Com o passar dos anos, segundo Fonseca e Filho [2016, p. 166],

[...] os calçadões foram se expandindo pela área central e, juntamente com as galerias, formaram um conjunto singular de espaços de passagem que permitem uma ampla variedade de caminhos a serem percorridos pelos fluxos contínuos de pedestres.

Atualmente, há três calçadões localizados no centro da cidade, sendo estes, o de parte da Rua Halfeld, o de parte da Rua Barão de São João Nepomuceno e o da Rua Mister Moore.
Realização:
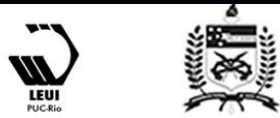


\section{$16^{\circ}$ \\ ERGODESIGN USIHC CINAHPA}

\subsection{Observação Participante}

A observação participante tem como finalidade aproximar o observador das circunstâncias, ocasiões, atitudes, reações, adversidades e todo e qualquer evento cotidiano, que possa gerar uma reflexão quanto ao uso e apropriação do espaço estudado. Neste trabalho, foi desenvolvida uma planilha de observação, para o registro, por meio de croquis e anotações, do comportamento das pessoas nos locais analisados.

A planilha possui um formato A4 e está dividida em quatro partes: cabeçalho; mapa, legenda; e anotações e croquis.

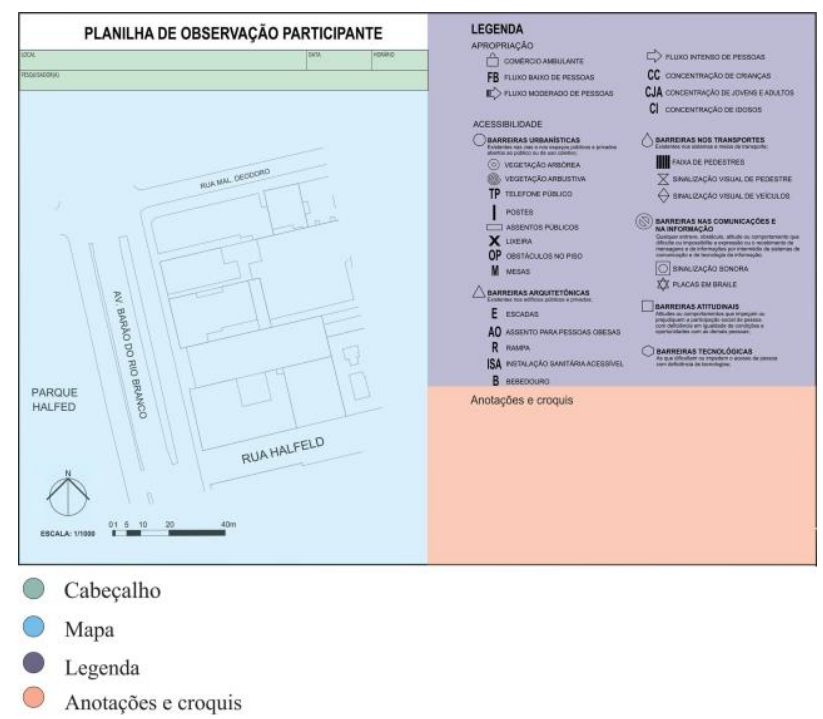

Figura 04 - Modelo da planilha de observação participante, com as quatro partes que a compõem evidenciadas. Fonte: arquivo próprio.

A primeira parte da planilha de observação participante diz respeito ao cabeçalho. Nele, devem ser identificados o local e o pesquisador, juntamente com a data.

Na segunda parte, está o mapa da área, a ser utilizado para as demarcações dos itens observados, especialmente mobiliário urbano e demais elementos existentes no local, fluxos, principais usos e áreas de permanência.

A terceira parte consiste na legenda - um suporte $16^{\circ}$ Ergodesign - Congresso Internacional de Ergonomia e Usabilidade de Interfaces Humano Tecnológica: Produto, Informações Ambientes Construídos e Transporte

$16^{\circ}$ USIHC - Congresso Internacional de Ergonomia e Usabilidade de Interfaces Humano Computador

CINAHPA | 2017 - Congresso Internacional de Ambientes Hipermídia para Aprendizagem.

aos registros a serem feitos no mapa. Nela, estão presentes questões tanto de apropriação, quanto de acessibilidade.

Já a quarta parte é reservada para anotações e croquis necessários à compreensão das questões verificadas em campo (Figura 04).

A observação participante deve ser aplicada nos períodos da manhã, tarde e noite, de segunda a sexta-feira, e no período da tarde, durante os sábados e domingos. Dessa forma, pretende-se aumentar as possibilidades de análise. Esse procedimento deve ser acompanhado por um levantamento fotográfico dos espaços. Uma vez coletados os dados, estes serão direcionados a uma planilha de análise (Figura 05).

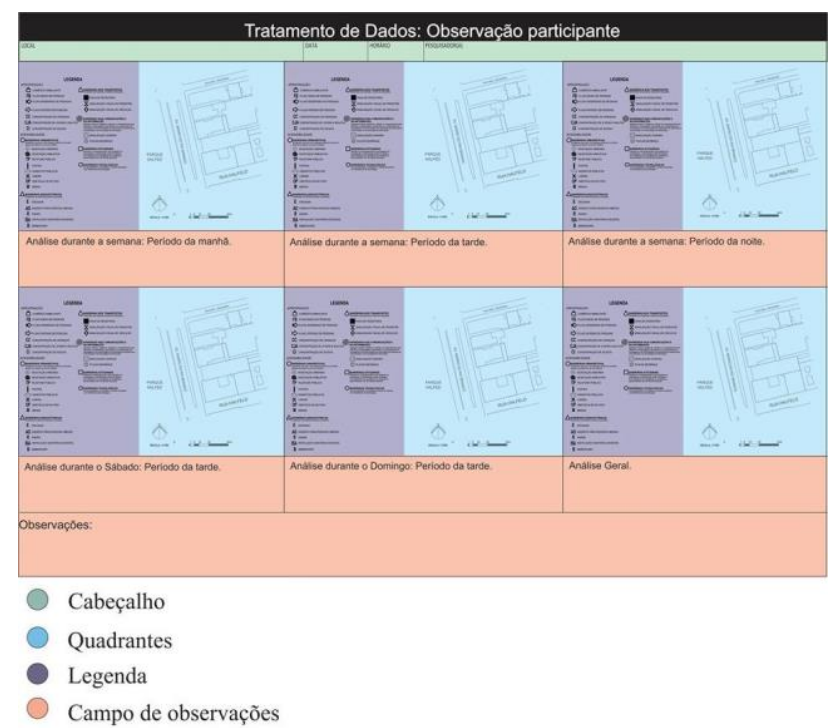

Figura 05 - Modelo da planilha de tratamento de dados da observação participante, com as quatro partes que a compõem evidenciadas. Fonte: arquivo próprio.

A planilha de tratamento de dados possui um formato $\mathrm{A} 3$ e é dividida em quatro partes.

A primeira é referente ao cabeçalho, no qual estão informações acerca da área estudada, do pesquisador e da data ou período de realização do tratamento dos dados.

A segunda parte contém seis quadrantes de análise do espaço. Cada um deles reúne os dados e 


\section{$16^{\circ}$ \\ ERGODESIGN USIHC CINAHPA}

anotações referentes a um dia e período de realização da observação.

A terceira parte corresponde à legenda - idêntica à legenda utilizada na planilha de observação - a ser adotada no preenchimento dos quadrantes.

A quarta e última parte diz respeito a um campo de observações gerais sobre a área.

\subsection{Entrevistas semi-estruturadas}

As entrevistas semi-estruturadas possuem como meta a coleta de dados sobre a percepção e o comportamento dos indivíduos nos espaços públicos urbanos. Uma vez verificadas, essas questões serão confrontadas com os pontos observados na planilha adotada na etapa anterior.

A aplicação dessa técnica está prevista para ocorrer simultaneamente à observação participante, na mesma área - distribuída ao longo dos mesmos períodos - e com igual duração. A amostra - referente aos participantes, em cada área estudada - deve ser composta por 100 pessoas.

A entrevista semi-estruturada é composta por questões simples, rápidas e diretas (Figura 06).

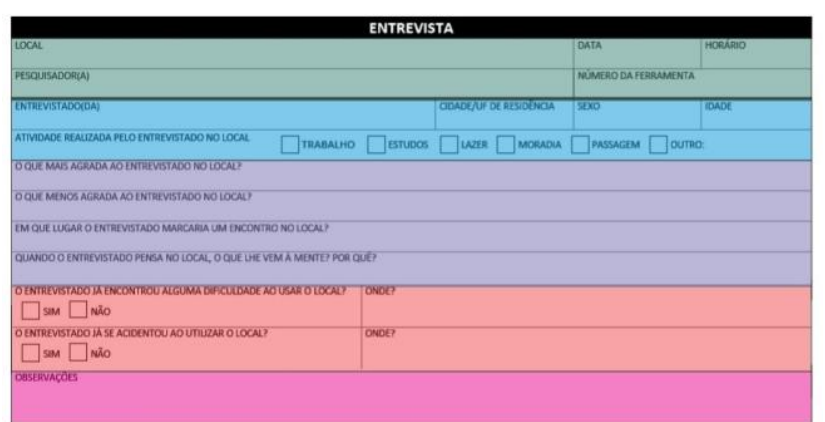

Cabeçalho

Caracterização da amostra

Questões acerca da apropriação

Questões acerca da acessibilidade

Observações

Figura 06 - Modelo de arquivo para entrevista, com as cinco partes que a compõem evidenciadas. Fonte: arquivo próprio.

A primeira parte corresponde ao cabeçalho, no qual devem estar informações relacionadas ao $16^{\circ}$ Ergodesign - Congresso Internacional de Ergonomia e Usabilidade de Interfaces Humano Tecnológica: Produto, Informações Ambientes Construídos e Transporte

$16^{\circ}$ USIHC - Congresso Internacional de Ergonomia e Usabilidade de Interfaces Humano Computador

CINAHPA | 2017 - Congresso Internacional de Ambientes Hipermídia para Aprendizagem.

local, data e horário de aplicação, número da entrevista e identificação do pesquisador.

A segunda parte diz respeito à caracterização da amostra, com nome, cidade na qual reside, sexo, idade e principal atividade realizada pelo entrevistado no local.

Na terceira parte, estão quatro questões relativas à apropriação do local pelo indivíduo, sendo elas:

(1) que mais o agrada no local; (2) o que menos o agrada no local; (3) onde, dentro daquela região, ele marcaria um encontro; e (4) que vem a mente do entrevistado quando pensa no local e o porque.

A quarta parte é reservada para possíveis observações.

O tratamento dos dados colhidos nas entrevistas deve ocorrer por meio de uma planilha em formato A3. Nela, será possível ter um panorama geral de todas as questões tratadas (Figura 07).

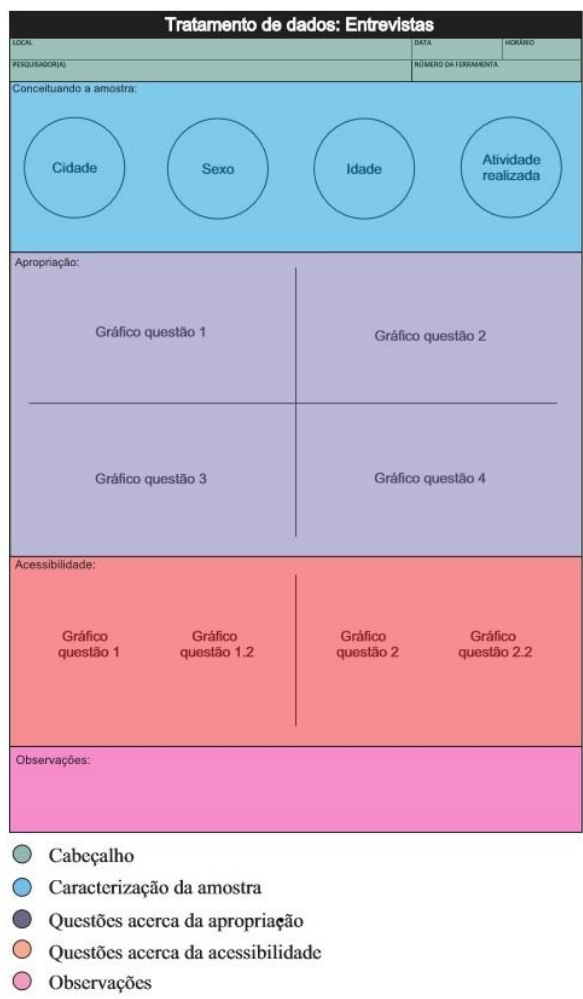

Figura 07 - Modelo da planilha de tratamento de dados das entrevistas sem dados gráficos, com as cinco partes que a compõem evidenciadas. Fonte: arquivo próprio.
Realização:
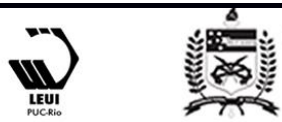


\section{$16^{\circ}$ \\ ERGODESIGN USIHC CINAHPA}

A primeira parte da planilha de tratamento dos dados das entrevistas corresponde ao cabeçalho, no qual devem constar informações referentes à área, ao pesquisador e à data de realização do trabalho.

A segunda parte contém gráficos, com número e porcentagem, relacionados à caracterização da amostra.

$\mathrm{Na}$ terceira parte, estão quatro quadrantes. Cada quadrante diz respeito a uma questão da entrevista, possuindo um gráfico, com número e porcentagem, com os dados obtidos.

$\mathrm{Na}$ quarta parte, devem ser reunidas as observações gerais.

A aplicação do instrumento de análise da apropriação aqui proposto deve ser acompanhada por um levantamento fotográfico da área estudada. A produção de fotografias dos espaços públicos, pois, pode contribuir para solucionar possíveis questões estabelecidas no tratamento dos dados e/ou ilustrar aspectos do comportamento das pessoas nesses locais.

Uma vez preenchidas as planilhas de tratamento de dados das observações participantes e das entrevistas semi-estruturadas, as conclusões alcançadas deverão ser confrontadas. Dessa forma, serão obtidos dados mais apurados acerca da percepção e do comportamento da pessoas nos espaços públicos considerados.

Está prevista a submissão do estudo ao Comitê de Ética, assim como a aplicação de um piloto, para revisão das técnicas adotadas.

Por fim, cabe aqui ressaltar que o instrumento proposto neste estudo deve ser periodicamente revisado, a fim de ser aprimorado.

\section{Considerações Finais}

A apropriação dos espaços públicos urbanos, está diretamente relacionada à identidade da cidade. É a partir desses locais que, além do convívio, do lazer e das demais atividades que comportam, a $16^{\circ}$ Ergodesign - Congresso Internacional de Ergonomia e Usabilidade de Interfaces Humano Tecnológica: Produto, Informações Ambientes Construídos e Transporte

$16^{\circ}$ USIHC - Congresso Internacional de Ergonomia e Usabilidade de Interfaces Humano Computador

CINAHPA | 2017 - Congresso Internacional de Ambientes Hipermídia para Aprendizagem.

população tem contato com os vários elementos do espaço urbano como, por exemplo, os edifícios.

A cidade de Juiz de Fora, município de médio porte, passa por transformações decorrentes do seu crescimento que acabam por afetar muitos de seus espaços públicos. Como consequência desse processo, a relação da população com a cidade pode ser alterada.

Neste ponto, estudos como o aqui apresentado podem contribuir com importantes dados e conclusões referentes a esse vínculo.

Sua primeira etapa - a observação participante - a partir do tratamento dos dados - oferece um panorama do comportamento das pessoas nos espaços públicos existentes em uma determinada área da cidade. Já a segunda etapa - a entrevista semi-estruturada - uma vez concluída, permite a obtenção de dados referentes à percepção dos indivíduos acerca dos mesmos locais.

A adoção de planilhas para o tratamento dos dados constitui um importante passo no sentido da otimização do processo de análise, uma vez que possibilita a apreensão de dados tanto gerais, quanto específicos. Assim, de posse das duas planilhas de tratamento dos dados - relacionadas às duas etapas - é possível comparar os resultados alcançados, referentes à maneira como os participantes do instrumento percebem e se comportam nos espaços públicos urbanos.

Ao mesmo tempo, a aplicação contínua da ferramenta em questão - abrangendo várias áreas da cidade - pode levar a uma leitura da apropriação do espaço urbano em uma escala maior - referente a bairros, por exemplo. Uma outra possibilidade que se apresenta é a de comparação entre bairros ou regiões da cidade.

O instrumento de análise da apropriação nos espaços públicos urbanos aqui descrito, pois, constitui uma oportunidade de obtenção de dados relevantes acerca da existência ou não de vínculos afetivos entre as pessoas e os espaços da cidade no caso, Juiz de Fora.

Dessa forma, esta ferramenta pode ser base para
Realização:

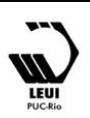


$16^{\circ}$ USIHC - Congresso Internacional de Ergonomia e Usabilidade de Interfaces Humano Computador

estudos e projetos subsequentes, voltados para a manutenção de um vínculo entre a população e os espaços públicos urbanos.

\section{BIBLIOGRAFIA}

ASSOCIAÇÃO BRASILEIRA DE NORMAS TÉCNICAS - ABNT. NBR 9050: Acessibilidade a edificações, mobiliário, espaços e equipamentos urbanos. Associação Brasileira de Normas Técnicas, Rio de Janeiro, 2015.

AUGÉ, M. Não-lugares. Introdução a uma antropologia da supermodernidade. 3. ed., Coleção Travessia do século. Campinas, Papirus, p. 73, 1994.

CAVAlCANTE, S., ELIAS, T. Temas básicos em psicologia ambiental. Vozes, Rio de Janeiro, p.63-69, 2011.

DEL RIO, Vicente. Cidade da mente, cidade real: percepção ambiental e revitalização na área portuária do RJ. p. 3-22. In: DEL RIO, Vicente; OLIVEIRA, Lívia de (Orgs.). Percepção ambiental: a experiência brasileira. $2^{\mathrm{a}}$ ed. São Paulo: Studio Nobel, 1999. 265 p.

FONSECA, F. L. da; FILHO, A. F. C. A supremacia do pesdestre: os calçadões e a qualidade urbana na área central de Juiz de Fora. Juiz de Fora: FUNALFA: Ed. UFJF, 2016.

HISRICH, R. D; PETERS, M. P; SHEPHERD, D. A. Empreendedorismo. $9^{a}$ ed. Porto Alegre: Editora McGraw-Hill, 2014.

MARCONI, M. D. A., LAKATOS, E. M. Fundamentos de metodologia científica. São Paulo: Atlas, 2003.

LEITE, R. P. Contra-usos da cidade: lugares e espaço público na experiência urbana contemporânea. Campinas: UNICAMP; Aracajú: UFS, 2004.

MANZINI, E. J. A entrevista na pesquisa social. Didática, São Paulo, v. 26/27, p. 149-158, 1990/1991. Disponível em:
https://www.marilia.unesp.br/Home/Instituicao/Do centes/EduardoManzini/Entrevista_na_pesquisa_s ocial.pdf. Acesso em: 18/03/2017.

MANZINI, E. J. Entrevista semi-estruturada: análise de objetivos e de roteiros. Seminário internacional sobre pesquisa e estudos qualitativos, v. 2, p. 10, 2004. Disponível em:

https://www.marilia.unesp.br/Home/Instituicao/Do centes/EduardoManzini/Manzini_2004_entrevista _semi-estruturada.pdf. Acesso em: 18/03/2017.

MENDONÇA, E. M. S. Apropriações do espaço público: alguns conceitos. Estudos e pesquisas em psicologia, v. 7, n. 2, p. 0-0, 2007.

NISHIKAWA, A. O espaço da rua articulado ao entorno habitacional em São Paulo. 1984.

Dissertação (Mestrado em Arquitetura e

Urbanismo) - Programa de Pós-graduação da

Faculdade de Arquitetura e Urbanismo,

Universidade de São Paulo, São Paulo, 1984.

OLINTO, P. Psicologia. Waissman koogan. Rio de Janeiro: Guanabara, s/d.

SANTOS, C. N. F.; VOGEL, A. Quando a rua vira casa: a apropriação de espaços de uso coletivo em um centro de bairro. Rio de Janeiro: FINEP/IBAM, Projeto, 1985.

SERPA, A. Espaço e Tempo (Online). GEOUSP, 2006.

TUAN, Y. Espaço e lugar: a perspectiva da experiência. Tradução: Lívia de Oliveira. São Paulo: Difel, 1983.

URIARTE, U. Espaço, Cultura e Identidade na Perspectiva da Antropologia Urbana. Mimeo, Salvador, 2001.

\section{Agradecimentos}

É importante agradecer à Pró-Reitoria de Graduação da Universidade Federal de Juiz de Fora, pelo suporte dado ao Projeto de Treinamento profissional: "Acessibilidade em edifícios e espaços públicos de Juiz de Fora", do qual este trabalho foi originado. Os agradecimentos são 


\section{$16^{\circ}$ \\ ERGODESIGN USIHC CINAHPA}

também ao professor coordenador do Projeto, Emmanuel Sá Resende Pedroso e aos acadêmicos Clara Andrade Vitoi, Layse Souza Costa e Pedro $16^{\circ}$ Ergodesign - Congresso Internacional de Ergonomia e Usabilidade de Interfaces Humano Tecnológica: Produto, Informações Ambientes Construídos e Transporte

$16^{\circ}$ USIHC - Congresso Internacional de Ergonomia e Usabilidade de Interfaces Humano Computador

CINAHPA | 2017 - Congresso Internacional de Ambientes Hipermídia para Aprendizagem.

de Faria Machado Eletherio, pela contribuição dada ao desenvolvimento do estudo aqui apresentado. 